\title{
SOBRE LA MEMORIA Y EL OLVIDO: LOS DIFUNTOS SELK'NAM Y EL CEMENTERIO DE LA MISIÓN SALESIANA NUESTRA SEÑORA DE LA CANDELARIA (RÍO GRANDE, TIERRA DEL FUEGO)
}

MELISA A. SALERNO ${ }^{a} \&$ RICARDO A. GUICHÓN ${ }^{b}$

\section{RESUMEN}

En este artículo nos aproximamos a la dinámica de la memoria y el olvido de los difuntos selk'nam en un caso particular del proceso colonial de Tierra del Fuego. Específicamente, centramos la atención en el cementerio de la misión salesiana Nuestra Señora de La Candelaria, en Río Grande. Este lugar nos permite abordar más de 100 años de historia, tejidos en torno a los indígenas fallecidos entre finales del siglo XIX y la primera mitad del siglo XX en el contexto de la institución. Inicialmente, analizamos las prácticas mortuorias (especialmente, aquéllas destinadas al tratamiento y disposición de los cuerpos muertos), y las formas en que algunas de ellas modelaron (y fueron modeladas por) la materialidad del espacio mortuorio. A partir de ello y, teniendo en cuenta la diversidad de actores, relaciones de poder y sentidos culturales puestos en juego, interpretamos las referidas tensiones entre memoria y olvido.

PALABRAS CLAVE: prácticas mortuorias, espacio mortuorio, memoria, olvido, selk'nam.

\section{ON MEMORY AND FORGETTING: THE SELK'NAM DECEASED AND THE CEMETERY OF THE SALESIAN MISSION NUESTRA SEÑORA DE LA CANDELARIA (RÍO GRANDE, TIERRA DEL FUEGO)}

\begin{abstract}
In this paper we intend to approach the dynamics of the memory and forgetting of the Selk'nam deceased in a particular case of the colonial process of Tierra del Fuego. We focus on the cemetery of the Salesian mission Nuestra Señora de La Candelaria, in Río Grande. This is where we can approach more than 100 years of history, built around the indigenous people who died between the end of the $19^{\text {th }}$ century and the first half of the $20^{\text {th }}$ century. First, we analyze mortuary practices (especially, the actions oriented towards the treatment and disposition of the bodies), and the ways in which some of them could have shaped (and could have been shaped by) mortuary space. Later,

Instituto Multidisciplinario de Historia y Ciencias Humanas (IMHICIHU-CONICET). melisa_salerno@yahoo.com.ar

b Núcleo de Estudios Interdiscipliarios sobre Poblaciones Humanas de Patagonia Austral (NEIPHPA, LEEH, FACSO-UNICEN). CONICET
\end{abstract}


and considering the diversity of social actors, power relations and cultural meanings, we interpret the above-mentioned tensions between memory and forgetting.

KEY WORDS: mortuary practices, mortuary space, memory, forgetting, selk'nam.

\section{INTRODUCCIÓN}

Iniciamos este trabajo planteando un interrogante: ¿Por qué interesarnos por la memoria y el olvido de los difuntos selk'nam; especialmente, la memoria y el olvido de aquéllos sepultados en el cementerio de la antigua misión de Río Grande (Tierra del Fuego, Argentina)? Para comenzar a responder esta pregunta, decidimos retrotraernos a nuestro propio collage de recuerdos.

Quienes se van sumando al proyecto arqueológico conducido en la misión Nuestra Señora de La Candelaria, no pueden olvidar su primer encuentro con el cementerio. En la entrada del lugar, un cartel oxidado reza: En este camposanto descansan los pioneros que posibilitaron los primeros pasos de la misión salesiana y los primeros capítulos de la historia de Río Grande. Esta referencia no parece incluir a los indígenas, que representan -según registros documentales- la mayor parte de los sepultados. En Argentina, el término "pionero" suele ser reservado para los colonos, haciendo a un lado a los habitantes originarios del territorio. cementerio parece abandonado. En el centro se divisa una gran cruz de metal. Sobre su pie, casi invisible para quien no se acerca lo suficiente, una placa indica: Una cruz mayor que identifica la presencia de una raza indígena con antiguos pobladores (Fig. 1).

Las tareas de relevamiento arrojaron datos interesantes. A nivel superficial, se identificaron 32 tumbas y tres lápidas aisladas. Las mismas se distribuyen a lo largo y ancho del cementerio (exceptuando la esquina sudoeste del mismo) (García Laborde et al. 2010; Salerno et al. 2017). En la mayor parte de los casos, se recuperó información sobre los difuntos. Según las lápidas, se trata de personas fallecidas entre las décadas de 1920 y 1940 (cuando el número de indígenas que vivía en La Candelaria se había reducido). La búsqueda de los nombres en los registros documentales sugirió -en la mayor parte de los casos- que estas personas no eran identificadas como selk'nam, sino como colonos, incluyendo Salesianos de Don Bosco e Hijas de María Auxiliadora. En líneas generales, los enterratorios de los indígenas se encontraban invisibilizados.
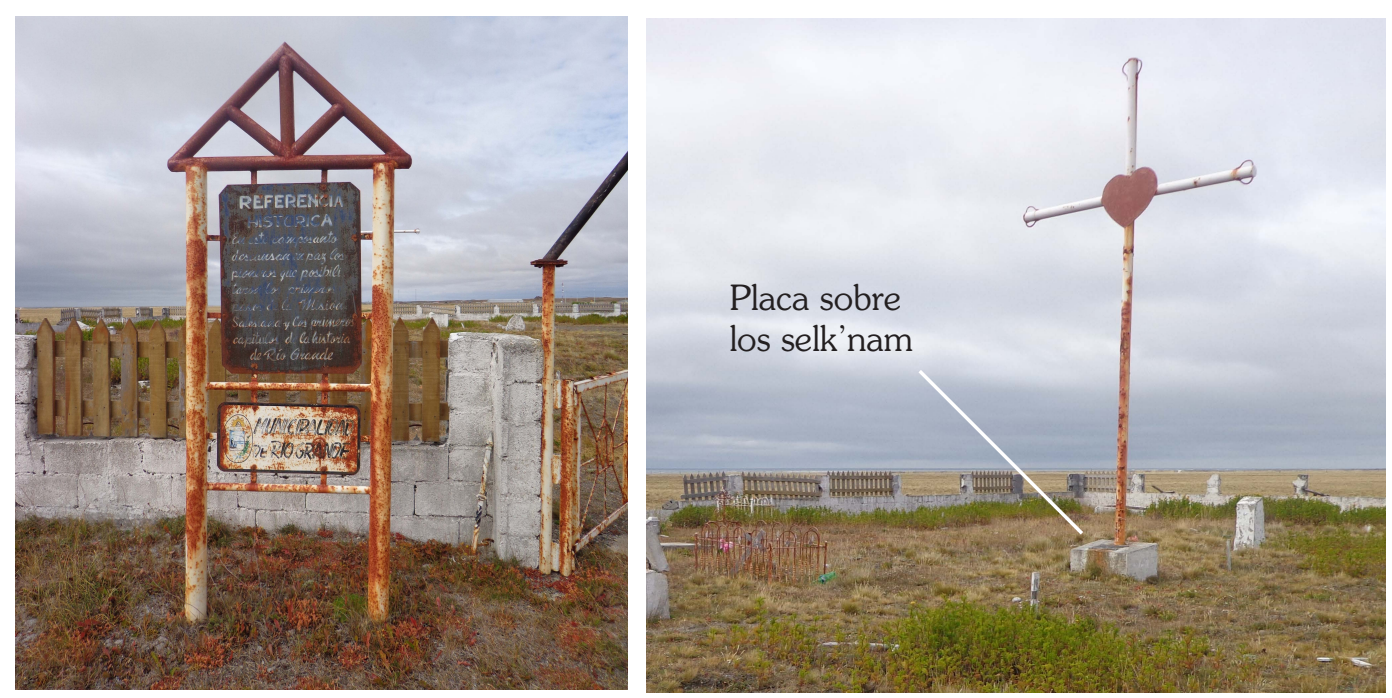

Fig. 1. Imágenes actuales del cementerio de La Candelaria en Río Grande. Izquierda: cartel de ingreso con referencias a los pioneros. Derecha: placa sobre los selk'nam (Fotografía M. Salerno, 2014). 
La primera idea que tuvimos fue que los selk'nam habían sido olvidados en el marco de una estrategia de dominación colonial por su mera condición de indígenas. Pero casi inmediatamente, surgieron otros interrogantes. ¿No estábamos entendiendo a los selk'nam como sujetos pasivos? ¿Podíamos simplemente decir que los agentes coloniales (especialmente, los miembros de la Congregación Salesiana) habían intentado "borrar" a los indígenas, cuando gran parte de lo que conocíamos sobre ellos era producto de sus registros? ¿La invisibilización de los fallecidos tan sólo dependía del hecho de ser indígena? Si esto era cierto, ¿qué podría haber sucedido con los colonos enterrados con anterioridad a 1920? La dinámica de la memoria y el olvido se disputaba en un contexto de relaciones coloniales mucho más complejo de lo que inicialmente habíamos imaginado.

En este trabajo decidimos indagar sobre la problemática. Para ello dividimos el texto en cuatro secciones diferentes. En la primera contextualizamos el caso de estudio; en la segunda definimos el marco teórico-metodológico que orienta el análisis; en la tercera efectuamos el estudio del cementerio, discutiendo las prácticas y el espacio mortuorio a lo largo del tiempo. Finalmente, en la cuarta sección $y$, atendiendo a la diversidad de actores, relaciones de poder y sentidos culturales puestos en juego, interpretamos los resultados obtenidos a la luz de la memoria y el olvido de los difuntos.

\section{CONTEXTUALIZACIÓN}

Tal como referimos, en esta sección reconstruimos el marco contextual de nuestro caso de estudio. Inicialmente, describimos los primeros pasos del proceso colonial en Tierra del Fuego (desde mediados del siglo XIX a mediados del siglo XX), abordando el rol desempeñado por distintos agentes colonizadores y su impacto sobre los indígenas. Posteriormente, consideramos la historia de La Candelaria, ofreciendo algunos datos sobre los selk'nam que vivieron, murieron y fueron inhumados en la institución.

\section{Relaciones coloniales en Tierra del Fuego}

Entre el siglo XVI y mediados del XIX, las interacciones entre los indígenas de Tierra del Fuego y los occidentales se limitaron mayoritariamente al "contacto" (sensu Silliman, 2005): una serie de encuentros cortos o eventuales, después de los cuales cada grupo mantenía su vida de forma más o menos independiente. Desde mediados del siglo XIX, el establecimiento de enclaves inauguró un período "colonial" (sensu Silliman, 2005); esto es, un escenario de "entrelazamientos" continuos (sensu Thomas, 1991) donde se vieron comprometidas "cuestiones de poder" en una escala novedosa (sensu Gosden, 2004). Diversos procesos resultaron convergentes: las políticas expansionistas de Argentina y Chile, la llegada de capitales europeos, y la fundación de misiones religiosas. Tierra del Fuego no vivió una era colonial como la de otras regiones americanas. No atestiguó el emplazamiento temprano de enclaves bajo el control político de Europa; ni sufrió la consecuente transición hacia un colonialismo interno. Por el contrario, fue colonizada en una fecha tardía por la doble acción de agentes europeos y nacionales (Guichón et al. 2017).

En lo que respecta a Argentina y Chile, el interés por el territorio sólo se manifestó cuando los estados lograron independizarse y dar los primeros pasos en su consolidación. Más allá de los viajes de exploración, diversas acciones reflejaron los intentos por declarar soberanía: las tomas de posesión del territorio, los conflictos por los límites, la fundación de los núcleos dinamizadores de la región (Floria, 1999). Sin embargo, a pesar de los esfuerzos efectuados, entre mediados del siglo XIX y principios del siglo $\mathrm{XX}$, los estados carecieron de fuerza suficiente y los proyectos liderados por capitales europeos tuvieron un mayor peso en la constitución de la realidad colonial. Si bien las empresas contaban con licencias de explotación otorgadas por los gobiernos, dentro de sus territorios las autoridades nacionales tenían poca injerencia (Martinic, 2001; Casali, 2011).

La explotación inicial de Tierra del Fuego cobró dos formas: la búsqueda de oro y la cría de ovejas (Borrero, 2001). La "fiebre del oro" se desató en el tercer cuarto del siglo XIX, cuando una comisión reportó el hallazgo de placeres auríferos. Si bien la actividad fue uno de los primeros hitos en la colonización del archipiélago, terminó agotándose al poco tiempo por no ser rentable (Belza, 1974). La 
presencia de los mineros supuso enfrentamientos; especialmente, por el robo de mujeres indígenas. Hacia fines del siglo XIX, diversos empresarios comenzaron a interesarse por la explotación ganadera. La cría de ovejas resultó un negocio productivo. El ingreso del ganado y el cercamiento de las propiedades conllevaron conflictos (Martinic, 1973). A medida que los guanacos resultaban desplazados, los nativos traspasaban los límites de las estancias para aprovisionarse de ovejas. Frente a estas circunstancias, los estancieros procuraron expulsarlos y hasta contrataron matadores profesionales.

En el siglo XIX, los viajeros refirieron a la existencia de cuatro pueblos en Tierra del Fuego. Dos de ellos eran canoeros y vivían de recursos marítimos: los yámana (yaganes) del canal de Beagle y el Cabo de Hornos y los kaweskar (alacalufes) de los canales occidentales. Los otros dos grupos eran los haush, que habitaban la península Mitre, y dependían del guanaco y recursos marítimos; y los selk'nam (onas), que ocupaban el interior de la Isla Grande y explotaban el guanaco. En un contexto de ideas evolucionistas, los pueblos de Tierra del Fuego fueron descritos como seres "primitivos" que vivían en condiciones miserables (Darwin, 2008 [1909]). Frente a estas declaraciones, los anglicanos y los salesianos comenzaron a interesarse por la región. Mientras los primeros establecieron una misión en Ushuaia (territorio yámana) (Bridges, 2000 [1948]), los salesianos fundaron otras dos: una en Isla Dawson (en territorio kaweskar) y otra en Río Grande (en pleno territorio selk'nam) (Martinic, 2011).

\section{Misión y muerte en Río Grande}

En junio de 1893 un grupo de salesianos encomendado por Monseñor Fagnano y, liderado por el Padre Beauvoir, se dirigió a la Isla Grande de Tierra del Fuego con el propósito de instalar una casa misional entre los selk'nam. Si bien el contingente debía desembarcar en Río Grande, no tuvo más remedio que hacerlo en San Sebastián por las condiciones de navegación. Habiendo perdido parte de sus provisiones, los religiosos construyeron un cobertizo en Arroyo Gama hasta que recibieron ayuda (Beauvoir, 1915). Finalmente, en noviembre del mismo año, remontaron el Río Grande y fundaron un primer establecimiento en Barrancos Negros. Al poco tiempo, comenzaron a acercarse los primeros indígenas. Sin embargo, como la zona era anegadiza, los salesianos decidieron trasladar la casa a un segundo emplazamiento, en el sitio conocido como Los Chorrillos (Fernández, 2014). En 1895, se sumaron las Hijas de María Auxiliadora. La misión permaneció en el lugar hasta que un incendio accidental redujo todo a cenizas en diciembre de 1896 (DMS I, 12/12/1896).

En julio de 1897 se definió un nuevo sitio para la institución (esta vez, cercano al Cabo Domingo), y se iniciaron las tareas de construcción (DMS I, 02/07/1897). En noviembre se efectivizó el traslado (DMS I, 06/11/1897). Ésta sería la localización definitiva de La Candelaria. Nuestro proyecto centra la atención en esta tercera instalación, considerando su rol protagónico en la historia de la misión. Hasta el momento, los trabajos se han orientado a discutir las condiciones de vida de los indígenas en el lugar, incluyendo la demografía, habitación, trabajo, enfermedad (Guichón et al. 2006; García Laborde et al. 2010; Casali, 2011; García Laborde, 2011). A continuación, referimos brevemente a los resultados obtenidos, entendiendo que constituyen un punto de partida para aproximarnos a la temática de la muerte.

En la misión, la mayor concentración de población se produjo entre 1899 y 1902. Este período coincidió con el desarrollo de los emprendimientos ganaderos y la persecución a los indígenas. Los selk'nam se acercaban buscando refugio, o los estancieros y la policía los trasladaban por la fuerza. Hasta 1899, los indígenas visitaban la institución por algunos días, estableciendo sus toldos en las cercanías. Posteriormente, pasaron a quedarse más tiempo (viviendo en "casitas" construidas para ellos o en los edificios del complejo central de La Candelaria (Martucci, 2016). Los indígenas que habitaban la misión eran mayoritariamente mujeres y niños. Hombres y mujeres desempeñaban tareas diferentes. Mientras los hombres colaboraban en la producción ganadera, y pasaban parte importante del tiempo al aire libre; las mujeres aprendían tareas vinculadas al tejido, y pasaban horas en talleres cerrados (Guichón et al. 2006; Casali, 2011).

Las nuevas condiciones de vida impactaron 
la salud de los selk'nam. La tuberculosis es la principal causa de muerte referida por los religiosos. Entre 1900 y 1902 los registros dan cuenta de una epidemia que habría afectado diferencialmente a mujeres y niños (Guichón et al. 2006; Casali, 2011). En la actualidad, el proyecto procura integrar los datos obtenidos mediante evidencia documental con el estudio del registro bioarqueológico humano (García Laborde et al. 2010; García Laborde, 2011). A partir de una decisión consensuada con los grupos interesados en la historia de la misión (comunidad selk'nam, religiosos de la Congregación Salesiana, descendientes de colonos, autoridades estatales), se exhumaron 33 cuerpos en el cementerio del tercer establecimiento. El análisis paleopatológico muestra señales compatibles con enfermedades infecciosas, pero los estudios moleculares sobre ADN de tuberculosis aún no han sido concluyentes (Guichón et al. 2014; Guichón et al. 2017).

Para aproximarnos a la muerte de los indígenas, proponemos considerar las defunciones $e$ inhumaciones en la misión. Hasta hace poco, el relevamiento atendía de manera exclusiva a los documentos misionales (García Moro, 1992; Casali, 2011). Los primeros estudios del proyecto de investigaciones se limitaron a abordar el período 1896-1931 (Casali, 2011; Guichón et al. 2017). Para el segmento 1896-1902, y a falta del Libro de Defunciones I (que está perdido), se registraron los decesos y/o inhumaciones presentes en el Diario de la Misión (DMS), la Crónica del Padre Zenone (CZ) y la Crónica de las Hijas de María Auxiliadora (CMA (Fernández, 2014). Para el segmento 19021931 se relevaron únicamente los decesos e inhumaciones del Libro de Defunciones II (LD II), esperando que fuera un registro exhaustivo. Así se estimó que, entre 1897 y 1931, 272 personas habían sido enterradas en el cementerio; que 251 correspondian a residentes de La Candelaria (siendo probablemente indígenas) y que 154 habían sido inhumadas entre 1897 y 1902 (dando cuenta de la "epidemia").

En un nuevo análisis decidimos integrar no sólo los datos provenientes de la evidencia documental (sumando un listado de sepulturas elaborado por el Padre Juan Ticó en la década de 1990), sino también la información provista por el relevamiento arqueológico del cementerio.
El abordaje procuró obtener datos para todo el período cubierto por las distintas líneas de evidencia, llevándonos desde 1895 a 1946 (del segundo al tercer establecimiento de la misión). En el relevamiento no se efectuaron distinciones entre segmentos temporales, dependiendo de la existencia o no del Libro de Defunciones II (en tanto se constató que no constituía un registro exhaustivo). El trabajo no está cerrado, por el contrario, representa nuestro estado actual de conocimiento sobre el tema (por lo que no dudamos que en el futuro encontraremos nuevas evidencias que permitan ampliar la base de datos confeccionada).

Hasta hoy, relevamos 385 defunciones (113 casos más que los cuantificados mediante estrategias previas). Resulta difícil precisar cuándo las personas comenzaron a ser enterradas en el cementerio del tercer establecimiento. La segunda instalación tuvo su propio camposanto (DMS II, 16/09/1904), y el mismo dejó de funcionar en algún momento entre la construcción y la inauguración de la nueva casa. Descontando las defunciones previas a la inauguración, contabilizamos 342 muertes. Todos los cuerpos fueron inhumados en el cementerio del tercer establecimiento (de ahora en más, "el cementerio", salvo indicación), exceptuando 10 casos sobre los que tenemos dudas o en los que el cuerpo debió ser dejado en otra localización.

Más de 250 personas fallecieron en la misión. Seguramente, la mayor parte de dichos difuntos fueron indígenas. Si bien entendemos que las identidades son realidades que no deben limitarse a las categorizaciones impuestas por un "otro", no podemos dejar de mencionar que en los documentos misionales un número importante de fallecidos fueron categorizados como "indios", "naturales de la Tierra del Fuego". Los registros también refieren a 8 salesianos e Hijas de María Auxiliadora. En unos 90 casos el lugar del deceso se produjo fuera de la misión o no pudo ser claramente definido por la falta de datos. Considerando las fechas en que se produjeron las muertes, y los apellidos y calificativos asociados a los difuntos, entendemos que parte importante de los mismos pudieron ser colonos o descendientes de estos últimos. Actualmente, los datos sobre decesos e inhumaciones continúan siendo analizados en profundidad, especialmente, a partir 
de la reconstrucción de biografías o historias de vida. Aquí tan sólo quisimos poner de relieve el lugar que tuvo la muerte de los selk'nam en el contexto de la misión.

\section{HERRAMIENTAS PARA EL ANÁLISIS}

Volviendo al objetivo de aproximarnos a la memoria y el olvido de los difuntos selk'nam, en esta sección presentamos el marco que orienta el análisis. Desde una perspectiva arqueológica, en el primer apartado consideramos algunos conceptos importantes para el trabajo. Así referimos a las relaciones coloniales y sus vínculos con el poder, la constitución de las prácticas y el espacio mortuorio, la memoria, el olvido y la pluralidad de sus sentidos. En el segundo apartado presentamos la metodología que permite abordar el cementerio. De esta manera, comentamos la decisión de segmentar su historia y describimos las líneas de evidencia y variables de estudio seleccionadas.

\section{Algunos conceptos}

Los trabajos tradicionales sobre el mundo colonial en arqueología entendieron el poder como una realidad centralizada. Mientras algunos actores lo poseían; otros simplemente carecían de él. El poder era igualado a la dominación, y la conquista era representada como el golpe fatal que los colonizadores asestaban sobre los colonizados. Como resultado de la ruptura con el pensamiento moderno (y colonial), se elaboraron diversas críticas. Si bien se continuó reconociendo que las relaciones coloniales estaban plagadas de asimetrías y violencia, también se señaló que la dominación no podía ser absoluta (Cusick, 1998). El poder pasó a ser definido como una realidad descentralizada. En el marco de relaciones dinámicas y multidireccionales (sensu Foucault, 1998 [1975]), el concepto de conquista comenzó a considerarse demasiado final y promotor de ideas como la de "extinción" de las culturas indígenas (cuando muchas de ellas continuaban presentes).

Desde su visión tradicional la arqueología centró casi exclusivamente su atención en el cambio cultural entre los grupos "dominados", apuntando las formas en que adoptaban las pautas de los "dominantes". La crítica abrió paso a nuevas ideas. Primero: que los actores en condiciones desfavorables también podían ejercer agencia y resistir (Taylor \& Pease, 1994); ya sea mediante eventos puntuales y de magnitud (como revueltas), o mediante acciones sutiles y fragmentarias (como la desobediencia frente a las normas impuestas por los colonizadores y el uso de sus códigos con fines distintos a aquéllos con que fueron creados) (De Certeau, 2000; Scott, 1985). Segundo: que las transformaciones en los modos de vida no sólo afectaban a los grupos colonizados. Específicamente, las "culturas del colonialismo" (sensu Thomas, 1991) suponían historias compartidas, intersecciones y espacios para la disputa, negociación y creatividad.

Las prácticas son acciones socialmente orientadas, que requieren la comprensión de las pautas presentes en el mundo cultural (Bourdieu, 1999). La muerte es un hecho universal y un momento significativo del ciclo de vida. Las prácticas mortuorias constituyen un conjunto de acciones variables destinadas a lidiar con la muerte (Williams, 2004) e incluyen los momentos previos al deceso, el tratamiento que se termina dando a los cuerpos, las manifestaciones de luto (Rakita et al. 2005). En este trabajo nos interesamos por las formas en que se prepara y dispone a los cuerpos muertos. Sin embargo, entendiendo que estas acciones forman parte de un conjunto más amplio, y que segmentarlo es resultado de una decisión analítica, evaluamos algunas otras con que pudieron relacionarse. Así, sopesando nuestro interés por la memoria y el olvido, también consideramos algunas acciones conectadas al luto.

Nuestra investigación se interesa por los aspectos materiales de la vida social. Específicamente, en este trabajo evaluamos la materialidad del espacio mortuorio. Bajo la influencia del pensamiento moderno, el espacio fue definido como un contenedor, dentro del cual los actores y las cosas ocupaban un lugar que podía ser definido de manera objetiva. A partir del desarrollo de propuestas críticas, el espacio pasó a ser considerado como un entramado, conformado por el paisaje, los actores, las cosas (Thomas, 2001). Asimismo, comenzó a ser discutido como producto y productor de prácticas. Por un lado, los investigadores señalaron que las acciones y su 
reiteración ayudaban a modelar la materialidad del propio espacio. Por el otro, subrayaron que el contacto familiar y reiterado con esa materialidad alentaba el aprendizaje y la transmisión de ciertas prácticas.

Las prácticas y el espacio mortuorio permiten reflexionar sobre la memoria y el olvido de los difuntos. En arqueología existen innumerables trabajos sobre la memoria (Jones, 2007), pero comparativamente menos sobre el olvido. Esto se asocia con diversos factores, incluyendo la obsesión de la modernidad con el registro y el mandato de la disciplina de reconstruir lo sucedido. Tradicionalmente se consideró que la memoria y el olvido constituían términos contrapuestos, asociados a valores jerarquizados (Huyssen, 2003). Mientras la memoria permitía trazar un arco entre pasado y presente, el olvido suponía su desintegración. Mientras la memoria era definida como positiva, el olvido era presentado como negativo (y asimilado a una carencia). En este escenario, los arqueólogos llegaron a establecer un "imperativo" de la memoria y una "lucha" contra el olvido.

Aquí adoptamos una posición más flexible. Así consideramos que la memoria y el olvido forman parte de una unidad dinámica que se encuentra en diálogo y tensión (sin suponer contradicción) (Buchli \& Lucas, 2001). No sólo es posible recordar ciertos eventos en la medida que otros sean olvidados. También algunas situaciones olvidadas pueden volver a ser recordadas (Ricoeur, 2004). Desde nuestra perspectiva, la memoria $y$ el olvido no son inherentemente positivos o negativos, sino que su valoración es contextual (Weinreich, 2004). Los profesionales no debemos trabajar bajo un imperativo universal de memoria. Por un lado, necesitamos reconocer que más allá de los esfuerzos por construir memoria, siempre hay algo que dejamos fuera. Por el otro, tenemos que comprender que la memoria (al igual que el olvido) deben ser consensuados con los grupos afectados (Salerno \& Zarankin, 2015).

\section{Consideraciones metodológicas}

Para aproximarnos a la memoria y el olvido de los difuntos selk'nam proponemos abordar la historia del cementerio de La Candelaria. Con el objetivo de ordenar la presentación, referimos a dos grandes períodos. El primero coincide con el funcionamiento del lugar; esto es, el lapso entre 1897 y 1946 en que se recibieron inhumaciones de manera activa. El segundo coincide con los momentos posteriores al funcionamiento del camposanto, y se extiende desde 1946 al presente. En la actualidad, contamos comparativamente con más información sobre el primer período (un resultado del interés del proyecto en los años de funcionamiento de la misión). Esperamos en un futuro cercano sumar datos sobre el período posterior, trabajando codo a codo con los grupos interesados.

En el marco de la investigación tendremos en cuenta los actores involucrados y las dinámicas de poder. Especialmente, atenderemos a las prácticas ligadas con el tratamiento y disposición de los cuerpos y sus relaciones con el espacio mortuorio. Primero: consideraremos las acciones que tuvieron como foco el cuerpo muerto en los momentos previos a su inhumación (uso de envolturas, contenedores, presentación del difunto). Segundo: contemplaremos las acciones que pudieron formar parte de la inhumación (selección del lugar de entierro; acompañamiento del cuerpo a dicha localización, demarcación de la sepultura). Tercero: abordaremos las acciones que sucedieron al enterratorio (visitas al cementerio, transformaciones en su materialidad, exhumaciones). En relación con este último punto, también evaluaremos las manifestaciones de luto.

La evidencia seleccionada es de carácter documental, por lo que dejamos para otro momento el abordaje del registro arqueológico. Los documentos analizados incluyen los registros inéditos de los religiosos que se encuentran en el museo de la misión (DMS, 1897-1947; CZ, 1898-1902; LD II, 1902-1947), una serie de registros publicados a principios del siglo XX (como los trabajos de Beauvoir y Gusinde), la Crónica traducida al castellano de las Hijas de María Auxiliadora (Fernández, 2014), algunas fotografías y filmaciones del cementerio, etc. Es cierto que los documentos se encuentran dominados por las voces de los no-indígenas. Sin embargo, el silenciamiento de los selk'nam puede ser (aunque sea parcialmente) revertido mediante 
el análisis de lo dicho y su contraste con lo no dicho, las notas marginales, las inconsistencias del registro.

\section{ANÁLISIS DEL CEMENTERIO}

\section{Período de funcionamiento del cementerio}

Para este período tenemos en consideración: 1) el lapso en que predominaron los enterratorios de residentes indígenas de la misión y 2) el lapso en que predominaron los enterratorios de colonos que vivían fuera de La Candelaria.

\section{Predominio de enterratorios indígenas}

Este lapso se extiende entre 1897 y 1920 , y coincide con el momento de mayor actividad en la misión (Casali, 2011). En esos años se produjeron más de dos tercios de las defunciones registradas. Más del 90 \% de esas muertes tuvieron lugar en La Candelaria, correspondiendo casi enteramente con indígenas. En este apartado centramos la atención en los enterratorios de los selk'nam y aportamos algunas referencias sobre aquéllos de los no-indígenas (entendiendo que el significado de los primeros sólo puede construirse de manera relacional). El lapso 1897-1920 resulta fundamental para discutir las dinámicas de poder en la misión. Así referimos a: 1.a) aquellas prácticas que -por distintos factores- pudieron ser impuestas por los religiosos y/o aceptadas por los selk'nam; 1.b) aquellas otras que contaron con posibles expresiones de agencia y resistencia indígena. Finalmente, también damos cuenta de la participación de diversos actores en las primeras exhumaciones conducidas en el lugar (1.c).

$\mathrm{Si}$ bien los documentos analizados corresponden al lapso 1897-1920, también incluimos referencias previas. Nuestro interés focaliza en el cementerio del tercer establecimiento, pero no queremos negar la existencia de otro camposanto en el segundo asentamiento, ni los posibles vínculos entre ambos.

1. a) Prácticas impuestas por los religiosos y/o aceptadas por los indígenas

Comencemos por las prácticas que fueron impuestas por los religiosos y/o aceptadas por los selk'nam. En su obra Los Shelk'nam, el Padre Beauvoir (1915, p. 209) inicia el apartado "Primera sepultura cristiana entre los onas" (que pudo tener lugar en la segunda instalación), diciendo: Fallecido que hubo [...] nos fué menester no abandonarlo, sino velarlo aquella noche, porque, según acostumbran los Indios, apenas ha fallecido uno [...] lo llevan a enterrar. Los religiosos querían evitar que los selk'nam administraran ciertos detalles de la práctica que consideraban contrarios al catolicismo. Y el primer paso para ello era recurrir al velatorio, tomando control sobre el cuerpo muerto y ganando margen para (re)organizar el ritual. Los registros disponibles para 1897-1920 sugieren la práctica del velatorio en casi todas las inhumaciones que cuentan con información sobre la fecha de muerte. Los documentos procuran reforzar la idea de que los religiosos organizaban el tratamiento de los fallecidos, mientras que los indígenas eran simples acompañantes.

Beauvoir (1915, p. 209) agrega: [E]l Hermano Carpintero hizo el ataúd y al día siguiente, encajonado el difunto, presentes sus hijos [...], le cantamos las exequias. Para los años 1897 a 1920 los diarios refieren prácticas semejantes, respetuosas de la liturgia de la Iglesia. Algunas entradas reconocen el uso de ataúdes: Hoy murió [una] mujer [...]. D. Dalmasso trabajó el ataúd (DMS I, 01/08/1904). Asimismo, indican que los fallecidos eran llevados a la Iglesia para celebrar misa en su honor: D. Borgatello cantó misa [ilegible] para el alma del niño [...] todos comulgaron en sufragio de la misma [...] Estaba presente el cadáver (DMS X, 25/08/1913). Las prácticas referidas contrastan con la tradición selk'nam. Por un lado, la utilización de cajones se diferenciaba de la costumbre de enterrar al finado únicamente envuelto con la piel de guanaco que había utilizado en vida. Por otra parte, el uso de fórmulas discursivas se distanciaba de la costumbre de no emplear palabras durante el tratamiento o disposición del cuerpo (ver Gallardo, 1919; Gusinde, 1982 [1939]).

Finalmente, Beauvoir refiere: procesionalmente lo hice llevar por [sus hijos] y con otros dos, acompañándolo todos los demás Indios con religiosa observancia, al sepulcro que de antemano habíamos hecho preparar. 
Los registros del período 1897-1920 repiten: [F]ue acompañado por todos los de la Misión al Cementerio, procesionalmente, rezando el S. Rosario (DMS X, 02/11/1913). El cementerio, producto y productor de prácticas específicas, transformaba de manera significativa algunas tradiciones selk'nam. Primero: el camposanto procuraba que los fallecidos fueran inhumados colectivamente en un mismo lugar y ya no en localizaciones individuales y dispersas. Segundo: el cementerio resultaba claramente identificable, a diferencia de lo que ocurría con los enterratorios indígenas, cuya huella -por precepto- debía ser borrada para que nadie pudiera reconocerlos. Tercero: el cementerio era conocido por todos los miembros de la comunidad, lo que se contraponía a las inhumaciones conducidas por un pequeño grupo de hombres (que mantenían en secreto su localización) (ver Gallardo, 1919; Gusinde, 1982 [1939]).

En cuanto a los momentos posteriores al enterratorio, los documentos aportan referencias sobre visitas reiteradas al cementerio. Por un lado, los religiosos procuraban que los residentes de la misión siguieran la prescripción de celebrar el Día de los Fieles Difuntos el 2 de noviembre: [P]or la tarde bendición y rezo del Rosario en procesión hasta el cementerio (DMS IX, 1-2/11/1909). Por otra parte, los salesianos comandaban las tareas de mantenimiento del lugar. La entrada del 16 de septiembre de 1900 (DMS I) refiere al ensanchamiento del camposanto (un hecho coincidente con el creciente número de muertes durante la "epidemia") y la del 17-18 de julio de 1913 (DMS X) da cuenta de arreglos en los cercos perimetrales. Mientras los hombres que oficiaban los enterratorios selk'nam evitaban que los miembros de su comunidad transitaran por el lugar en que habían ocultado las sepulturas (ver Gusinde 1982, [1939]), los religiosos querían que los residentes regresaran al cementerio para honrar a los difuntos.

Otros actores -además de indígenas y religiosos- modelaron la práctica mortuoria. Según el Juez de Paz y Encargado del Registro Civil de San Sebastián (DMS I, 20/03/1902), la pequeña Acta declaración que [la misión debe] levantar [...] con arreglo al Arto. 74, con más el sitio donde se haya enterrado el cadáver [...] debe mandarse al Comisario del Departamento para que con el Certificado que éste debe expedir [se] proced[a] a la suscripción en este Registro. Desde 1902, las muertes en La Candelaria no debían quedar sin registro. Si bien con anterioridad a esa fecha los religiosos apuntaban los decesos, de ahí en más, se ordenó que lo hicieran sistemáticamente y lo comunicaran de manera oficial. El Libro de Defunciones II podría constatar, hasta cierto punto (en tanto no todas las defunciones fueron consignadas), esta tendencia. Los fallecidos fueron individualizados, indicando nombre, parentesco, fecha de muerte, causa del deceso. El contenido del documento debía corresponder, además, con la materialidad de un cuerpo localizable en el espacio. Si bien el Libro redunda en fórmulas como fue sepultado en el cementerio, lo cierto es que no brinda mayores datos.

\section{1. b) Posibles expresiones de agencia y resistencia indígena}

En su apartado Sepultura, Beauvoir (1915, p. 210) da cuenta de una defunción ocurrida días antes de la Primera sepultura cristiana.... En ese contexto, un padre afligido por la enfermedad de su hijo supuestamente le presta el servicio de ahogarlo para terminar su sufrimiento. El religioso apunta: [C]iego de dolor, agarra el exánime cuerpecito y se huye a toda carrera. Cuando llegamos nosotros, ya estaba muy lejos, había ido a sepultarle. Más allá del temor de efectuar una acción condenada por los salesianos, este pasaje revela que el ímpetu de velar a los difuntos podría haber correspondido con la decisión de algunos indígenas de escapar con los cuerpos para enterrarlos según sus costumbres. En lo que concierne a la preparación de los difuntos, resulta interesante retomar el apartado Primera sepultura cristiana... Después de referir a las dimensiones católicas del enterratorio, Beauvoir reconoce que el cuerpo fue envuelto de manera tradicional en su capa de guanaco (independientemente de haber sido colocado en un ataúd). Lamentablemente, los documentos del período 1897-1920 no aportan información sobre el tema.

En lo que toca a las inhumaciones, nos interesa citar las impresiones de Gusinde (1920a, p. 19). Llegado a la misión para efectuar 
observaciones etnográficas, encuentra que estaba despoblada y decide realizar trabajos donde tristemente podía encontrar mayor cantidad de selk'nam: el cementerio. En ese entonces, desiste de exhumar por considerar que: [J]unto con los indios, fueron también enterrados allí, sin orden alguno, aquellos civilizados que morían en los alrededores. No se encontraban ni rastros de inscripciones o indicios de su colocación, mucho menos existían registros sobre los entierros. Este relato nos transmite la impresión de que el cementerio no se encontraba segmentado con el propósito de ordenar a los difuntos (por criterios sociales, cronológicos, etc.). Además, nos enfrenta a la pregunta de si los enterratorios tuvieron originalmente alguna señalización, que se perdió con el tiempo (sin que hubiera interés por reemplazarla). El DMS sugiere que entre 1897-1920 no se efectuaron demarcaciones importantes (sólo se habla del "cerco" de la tumba de un personaje de renombre, el padre del aviador Jorge Newbery -DMS IV, 12/05/1906). Mientras tanto, las palabras de Gusinde sostienen que la invisibilidad habría sido compartida por indígenas y colonos.

Finalmente, en cuanto a las formas de sobrellevar el luto, las Hijas de María Auxiliadora indican para el segundo establecimiento de la misión (CMA, 05-06-1895 -Fernández, 2014, p. XXX): Tenía la cara tan pintada de negro que apenas se podian ver los ojos blancos [...]; el Director nos dijo que esta pobre mujer estaba haciendo el luto porque había muerto su madre; para hacer mayor luto se tajean las piernas con trozos de vidrio y esta función la hacen todos los días, mañana y tarde mientras dura el tiempo de duelo... Casi para el mismo momento, Beauvoir añade: Es costumbre de estos indios [...] quemarle toda la casa y todo cuanto le había pertenecido [al muerto] [...] [T]ratamos de impedir que incendiasen la choza [...] sólo sí, se le permitió quemasen los trastos. Para el período 1897-1920, encontramos otras referencias sobre la quema de objetos. Otras entradas dan cuenta de la partida de los selk'nam tras la muerte de un miembro del grupo: Por el luto de la muerte de [un] niño se fueron [...] Total 14 indios por todos (DMS $\mathrm{X}, 24 / 06 / 1913)$. Esto resultaría coincidente con la tradición de abandonar el campamento donde habría vivido el difunto.

1.c) Primeras exhumaciones conducidas en La Candelaria

Durante el predominio de enterratorios indígenas especialmente, entre 1910 y 1920, el cementerio atestiguó las primeras exhumaciones. En su Primera Expedición, Gusinde (1920a, p. 19) desistió de realizar tareas en el lugar no sólo por la ausencia de demarcaciones, sino también porque: [T]anto la policía estacionada en aquel puerto, como también el señor Carlos Gallardo, comisionado por el Gobierno argentino, hace pocos años [...] habían buscado restos [...] Aquel cementerio chico ha sido revuelto asi tantas veces. La acción de la policía es referida por los salesianos: Vienen el Sr. De la Colina y Comisario con vigilantes a revolver el cementerio sacando los esqueletos que quisieron pues nada dijeron a los de la Misión (DMS XI, 30-04-1916). En su Segunda Expedición, Gusinde (1920b, p. 155) se decide a exhumar: [P]robé suerte, escarbando en varios puntos; pero en ninguna parte el suelo se había visto libre de anteriores trabajos, y desistí.

Las acciones mencionadas deben ser entendidas en un contexto colonial, incluyendo las ideas que las ciencias humanas tenían sobre los selk'nam. Prácticamente desde fines del siglo XIX, cuando comenzaron a establecerse los primeros enclaves, los occidentales se convencieron de que los indígenas estaban condenados a desaparecer. La antropología consideró que tenía el deber de preservar lo que quedara de ellos, aunque más no fueran sus cuerpos muertos. Las exhumaciones eran llevadas a cabo sin consultar a los sobrevivientes ni evaluar el impacto que las acciones tenían sobre ellos. Gusinde (1982 [1939], p. 159) señala: La actitud amenazadora que adoptaban cuando algunos blancos trataban de cavar en los cementerios de la estación misionera, en busca de esqueletos, a plena luz del día y bajo sus propios ojos, tiene su origen en la suposición que estos europeos -enemigos por principio- querian llevarse las osamentas para profanarlas.

Los esqueletos obtenidos en el cementerio de la misión y otros lugares alimentaron las colecciones de Buenos Aires y otras partes del mundo. Si bien 
los comisionados científicos contaban con el aval de los gobiernos, desconocemos si la policía respondía a directivas del Estado o a un negocio privado. Resulta oportuno mencionar que las exhumaciones de la misión estuvieron acompañadas por acciones más virulentas. Tal como referimos, durante principios del siglo XX, los estancieros persiguieron a los selk'nam que traspasaban sus cercados y se alimentaban de las ovejas. Así se desarrollaron matanzas, donde los asesinos recibían un pago por cantidad de indígenas aniquilados. Gusinde (1951, p. 100) enfatiza: Enviaban los cráneos de los indios asesinados al Museo de Antropología de Londres, el cual pagaba hasta ocho libras esterlinas por cabeza.

\section{2- Predominio de enterratorios de colonos}

Este segundo lapso se extiende aproximadamente desde 1920 a 1946 y coincide con el aumento de los colonos en Río Grande y el declive de los indígenas que vivían en la misión (al punto que para fines de la década de 1920 se habla de trocar La Candelaria en Escuela Agrícola, y que dicha institución se inaugura en 1946 -DMS XIV, 04/02/1928; DMS XXI, 10/1946). Según los documentos, durante este período se produjeron menos de un tercio del total de las defunciones registradas. En aproximadamente $75 \%$ de dichos casos, las muertes se produjeron fuera de La Candelaria o no se aportan datos sobre el lugar de deceso. Tal como referimos anteriormente, parte significativa de esos difuntos pudieron ser colonos o descendientes de los mismos. Mientras tanto, un
$25 \%$ de las personas murieron en el contexto de la misión. Siendo 8 difuntos salesianos e Hijas de María Auxiliadora, se considera que la mayor parte de los restantes habrían sido indígenas.

El lapso 1920-1946 se caracteriza por el predominio de enterratorios de colonos, aunque las inhumaciones selk'nam no habrían sido tan escasas comolas de no-indígenas durante el período anterior. La información sobre las prácticas mortuorias, tanto para los selk'nam como para los colonos, es escasa. Los documentos sugieren adhesión a las pautas católicas (vigilia, exequias, acompañamiento del cuerpo al cementerio), sin brindar datos sobre disidencias. En el caso de los selk'nam, o bien el registro omite continuar refiriendo a resistencias (como lo habría hecho para 1897-1920), o bien las prácticas adquirieron un matiz diferente. Probablemente, una de las principales diferencias con respecto al lapso anterior haya residido en la importancia brindada a la identificación de los enterratorios. Considerando que hasta 1920 Gusinde refería a la ausencia de demarcaciones, es posible que en momentos posteriores su número haya crecido, o que existiera mayor preocupación por su perdurabilidad y mantenimiento.

El cambio en la materialidad del cementerio podría ser sugerido por diversas fuentes. Primero: en los registros escritos se menciona reiteradamente la instalación de estructuras y lápidas (DMS XIV, 31-10-1921). Segundo: una filmación realizada en 1968 muestra la existencia de numerosas sepulturas en madera y cemento (Chapman \& Montes, 1977) (Fig. 2). No resultaría extraño que colonos y selk'nam hayan sido acompañados por

Fig. 2. Capturas del documental de Chapman y Montes (1977), donde se observan numerosas estructuras que demarcan sepulturas en el cementerio.
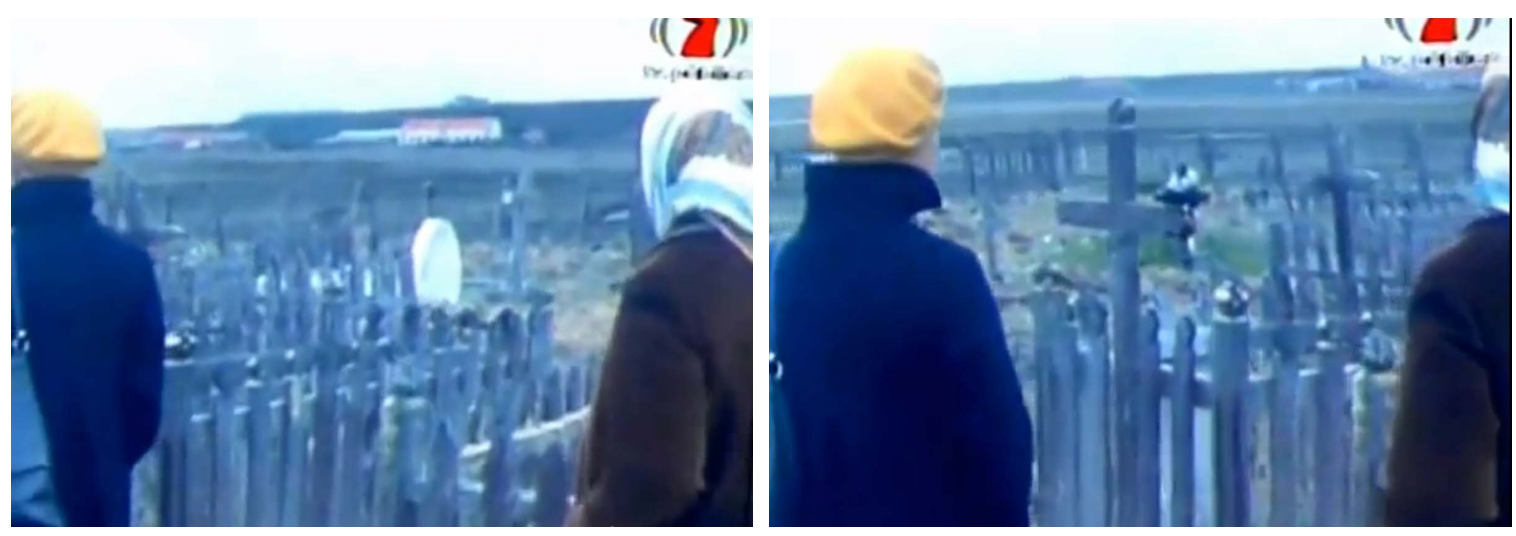
estructuras diferentes (mientras las tumbas de los colonos pudieron ser elaboradas en materiales más costosos y perdurables, las de los indígenas pudieron ser confeccionadas en otros más económicos y perecederos). Tercero: los trabajos de prospección conducidos por el equipo en el cementerio permitieron identificar estructuras en pie, posteriores a 1920 , de materiales perdurables como cemento, mármol y metal y pertenecientes mayoritariamente a religiosos y otros colonos.

\section{Período posterior al \\ funcionamiento del cementerio}

Para este segundo momento, consideramos: 1) el posible traslado de cuerpos al nuevo cementerio de la ciudad, 2) la remodelación del camposanto, 3) las tareas conducidas por el proyecto de investigación.

\section{1-Posibles traslados a un nuevo cementerio}

Hasta el momento, la última defunción sobre la que tenemos información es de 1946. Sin embargo, es probable que el relevamiento de nuevos documentos (como las actas de defunción del Registro Civil) empuje más allá esta fecha. En 1945, los documentos refieren a un nuevo cementerio que los salesianos habrían ido a bendecir (DMS XXI, 11/03/1945). Desde finales de la década de 1940 y, según testimonios orales, algunos familiares pudieron trasladar a sus seres queridos desde el camposanto de la misión al Cementerio Municipal de Río Grande. Las exhumaciones pudieron provocar la remoción de algunas estructuras. Un estudio sistemático sobre los posibles traslados aún debe ser realizado, teniendo en cuenta los ingresos registrados en el cementerio municipal.

\section{2- Remodelación del camposanto}

Tal como referimos, el documental de Chapman y Montes (1977) ilustra un cementerio con numerosas estructuras. Poco más de una década después, Ricardo Guichón visitó La Candelaria y tomó algunas fotografías del camposanto (Fig. 3). Si se comparan las imágenes, cuesta creer que se trata del mismo lugar. Según testimonios orales, en

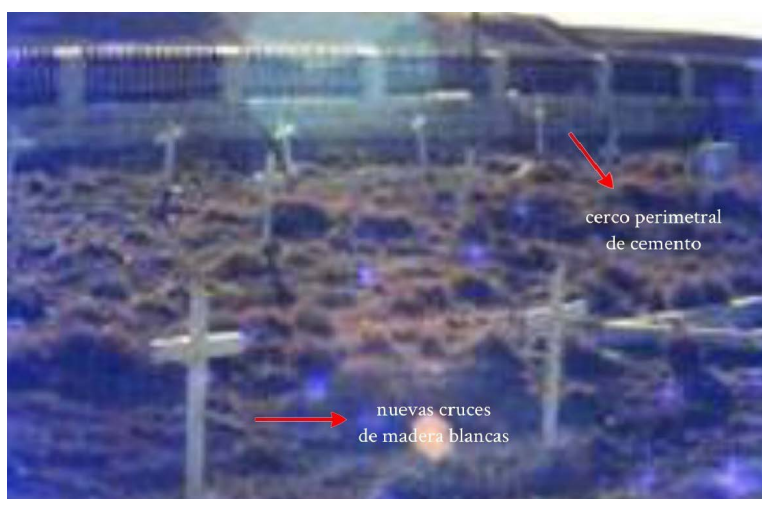

Fig. 3. Imágenes tomadas por Ricardo Guichón en 1984, donde resulta posible apreciar transformaciones significativas en el espacio mortuorio.

algún momento entre la captura de ambos conjuntos de imágenes, se produjo una remodelación integral del cementerio. En un intento de "modernización", el cerco perimetral de madera fue reemplazado por uno de cemento y muchos corralitos del mismo material que demarcaban sepulturas fueron removidos. Especialmente, sobrevivieron las estructuras de cemento, mármol y metal. Además, se distribuyeron de manera homogénea cruces pintadas de blanco (sin responder necesariamente a la localización de los antiguos corralitos). Nos preguntamos si este movimiento no pudo afectar diferencialmente las sepulturas de los selk'nam, ya que -al menos en la actualidad- no resultan claramente identificables.

\section{Tareas arqueológicas}

Las tareas arqueológicas comenzaron en la primera década del milenio. El trabajo contó con el interés de los grupos comprometidos con la historia de la misión: autoridades de pueblos originarios, descendientes de colonos (Centro de Antiguos Pobladores), miembros de la Congregación Salesiana y autoridades estatales. Entre 2007 y 2013 se efectuaron cinco campañas arqueológicas. El sector elegido fue un rincón sin estructuras, donde se esperaba encontrar indígenas cuyos enterratorios no resultaban visibles en superficie. El análisis de los cuerpos y materiales ha sido y será presentado en otras publicaciones (García Laborde et al. 2010; García Laborde, 2011). Si bien inicialmente las investigaciones se interesaron por conocer la salud y enfermedad de los selk'nam, con 
el correr del tiempo se agregaron nuevos desafíos. Así se comenzaron a discutir temas sensibles para los pueblos originarios, como la dinámica de las identidades, las relaciones de poder, el impacto de la historia colonial en la desigualdad y discriminación en el presente, etc.

\section{ALGUNAS INTERPRETACIONES}

La memoria y el olvido de los selk'nam inhumados en La Candelaria forma parte de un proceso complejo, que involucró diversos actores, entrelazados por relaciones de poder y sentidos variados.

Tradicionalmente las prácticas de los indígenas daban cuenta de los intentos por borrar la huella material de los difuntos. La muerte de un familiar era vivida con extremo pesar. El luto incluía prácticas angustiosas. En este escenario, la comunidad intentaba proveer herramientas para mitigar el dolor. Olvidar por completo a los seres queridos resultaba imposible. Pero los intentos por desdibujar materialmente su presencia procuraban romper con el círculo de la evocación: abandonar el campamento donde se había producido el deceso, disimular/desconocer el lugar de sepultura, evitar mencionar el nombre del difunto (o referir a él usando circunloquios) (Gallardo, 1919; Gusinde, 1982 [1939]). A lo largo de las generaciones la memoria de los actores singulares retrocedía y la memoria de los antepasados se reforzaba como colectivo, alentando la integración con el cosmos.

El establecimiento de la misión impactó la dinámica referida. Las prácticas y el espacio mortuorio formaron parte de negociaciones. Los religiosos insistieron en enterrar a los difuntos en el cementerio porque querían que se los recordara como católicos (testigos de su obra). Como herederos del pensamiento cristiano y moderno, consideraban relevante que los sobrevivientes mantuvieran una conexión material con sus seres queridos y confiaban en que parte de esa relación se produjera y reprodujera por intermedio del cementerio. Desde esta forma de percibir el mundo, entendieron que evocar a los fallecidos podía ser reconfortante (pues habían entrado en el reino de Dios), a la vez que podía evitar que el individuo se perdiera en el olvido (algo percibido como negativo). Nos enfrentamos a dos maneras de sobrellevar el duelo y de entender a la persona tras la muerte.

Puede que inicialmente algunos indígenas intentaran escapar a la huella de los enterratorios, sacando los cuerpos de la misión antes que los religiosos los inhumaran. Especial atención merece la referencia de Gusinde a la falta de demarcaciones en el cementerio. Por un lado, los indígenas pudieron no estar interesados en la individualización de los enterratorios (algo que rompía con el colectivo de los antepasados). Por otra parte, los religiosos pudieron desistir de demarcar las sepulturas o mantener sus huellas. Esto pudo enfrentarlos a diversas alternativas. Primero: librar la práctica a negociación, considerando que no atentaba significativamente contra el propósito de construir un cementerio católico. Segundo: percibir como innecesario reconocer a los difuntos selk'nam como individuos tras la muerte (con las connotaciones que esta modalidad de persona supone para Occidente) (Salerno, 2011). Aquí se pone en juego la idea de quién se considera digno de ser recordado. Lo interesante es que otros sujetos coloniales pudieron correr la misma suerte.

Entre 1910 y 1920 la materialidad del cementerio y la dinámica de la memoria y el olvido fueron impactadas por otros actores. Como ya relatamos, en las primeras décadas del siglo XX, la ciencia temió por la extinción de los selk'nam. Así terminó generando un imperativo de memoria: elaborar un registro de estos pueblos a cualquier costo. ¿Será que la violencia ejercida sobre los cuerpos muertos y los sobrevivientes, sumado al recuerdo de las cientos de defunciones por enfermedad, alejaron a los selk'nam de la misión? Los relatos sugieren que los indígenas identificaban el lugar con la muerte. ¿La Candelaria fue abandonada como los campamentos donde habían vivido los fallecidos y evadida como los enterratorios donde restaban los cuerpos? ¿Pudo ser ésta una forma de manejar el dolor provocado por la materialidad de una memoria implacable?

Es probable que entre 1920 y 1946 el cementerio haya atestiguado el crecimiento de estructuras que demarcaban enterratorios y que las sepulturas de colonos e indígenas hayan sido construidas en materiales diferentes. Más allá de las desigualdades económicas, ¿podrían encontrarse aquí otros testimonios de una memoria que se resiste 
al olvido y otra que reconoce y acepta sus límites? La remodelación del cementerio quizás puso a prueba la pregunta. Las sepulturas de cemento, asociadas a los colonos, lograron sobrevivir. Las decisiones de los no-indígenas pudieron forzar el olvido de los enterratorios selk'nam. Pero quizás, de una manera paradójica, los antiguos preceptos de los indígenas resultaron victoriosos: se terminaron borrando las huellas de la muerte.

Actualmente el escenario es otro: los descendientes de pueblos originarios están planteando nuevas agendas. Nuestros olvidos y recuerdos como sociedad (multi-inter-trans-cultural) forman parte de complejos entramados donde, al igual que en el pasado, se combinan tensiones, contradicciones y conflictos. Qué olvidar y qué recordar sobre los fallecidos puede ser también pensado, percibido y habitado como un espacio de encuentro. Cómo dar lugar a nuevos modos de existir, sentir y convivir es parte de nuestros actuales desafíos como sociedad.

\section{AGRADECIMIENTOS}

A los miembros del equipo de investigación. A la comunidad local especialmente, a los colectivos selk'nam, al "Centro de Antiguos Pobladores", a la escuela salesiana "Nuestra Señora de la Candelaria", a las autoridades municipales y provinciales. Las ideas volcadas en el artículo son de nuestra exclusiva responsabilidad. Agradecemos a CONICET por el apoyo brindado. El trabajo contó con financiamiento de ANPCyT.

\section{BIBLIOGRAFÍA}

Belza, J. (1974). En la Isla del Fuego. 1. Encuentros. Buenos Aires: Instituto de Investigaciones Históricas de Tierra del Fuego.

Bourdieu, P. (1999). Meditaciones pascalianas. Barcelona: Anagrama.

Buchli, V., \& Lucas, G. (2001). Between remembering and forgetting. En Buchli, V. \& Lucas, G. (Eds.), Archaeologies of the contemporary past (pp. 79-83). London: Routledge.

Borrero, L. (2001). Los Selk'nam. Buenos Aires: Galerna.

Casali, R. (2011). Contacto interétnico en el norte de Tierra del Fuego: La misión salesiana La Candelaria y la salud de la población selk'nam. (Tesis de doctorado en historia).
UNMDP, Mar del Plata.

Chapman, A., \& Montes, A. (1977). Los onas. Vida y muerte en Tierra del Fuego. Video documental, 55 min.

Cusick, J. (1998). Historiography of acculturation. En Cussick (Ed.), Studies in culture contact (pp. 126-145). Carbondale: Southern Illinois University.

De Certeau, M. (2000). La invención de lo cotidiano, vol. I. México DF: Universidad Iberoamericana.

Floria, P. (1999). Historia de la Patagonia. Buenos Aires: Editorial de Ciencia y Cultura.

Foucault, M. (1998 [1975]). Vigilar y castigar. Buenos Aires, Siglo Veintiuno.

García Laborde, P. (2011). El cementerio de la antigua misión salesiana Nuestra Señora de La Candelaria. Bioarqueología de contacto en el siglo XIX-XX. (Tesis inédita de licenciatura en arqueología). UNCPBA, Olavarría

García Laborde, P., Suby, J., Guichón, R., \& Casali, R. (2010). El antiguo cementerio de la misión de Río Grande, Tierra del Fuego. Primeros resultados sobre patologías nutricionales-metabólicas e infecciosas. Revista Argentina de Antropología Biológica, 12(1), 57-69.

García Moro, C. (1992). Reconstrucción del proceso de extinción de los selk'nam a través de los datos misionales. Anales del Instituto de la Patagonia, 21, 33-46.

Gosden, C. (2004). Archaeology and colonialism. Cambridge: Cambridge University Press.

Guichón, R., Casali, R., García Laborde, P., Valenzuela, L., Martucci, M., \& Motti, J. (2014). Escenario epidemiológico-sanitario fueguino (1880-1930): Los alccances de la tuberculosis en la población de La Candelaria y Ushuaia a partir de un examen histórico y bioarqueológico. Trabajo presentado en las IX Jornadas de Arqueología de la Patagonia. Coyhaique, Chile, 20 al 25 de octubre.

Guichón, R., Casali, R., García Laborde, P., Salerno, M., \& Guichón, R. (2017). Double coloniality in Tierra del Fuego, Argentina: A bioarchaeological and historiographical approach to Selk'nam demographics and health (La Candelaria mission, late 19th and early 20th centuries). En Murphy, M. \& Klauss, H. (Eds.), Colonized bodies, world transformed. Toward a global bioarchaeology of contact and colonialism (pp. 197-225). Gainesville: University Press of Florida.

Guichón, R., Suby, J., Casali, R., \& Fugassa, M. (2006). Health at the time of Native-European contact in Southern Patagonia. First steps, results and prospects. Memoria Instituto Oswaldo Cruz, 101(2), 97-105.

Huyssen, A. (2003). Present pasts. Stanford: Stanford University 
Press.

Jones, A. (2007). Memory and material culture. Cambridge: Cambridge University Press.

Martinic, M. (1973). Panorama de la colonización en Tierra del Fuego entre 1881-1900. Anales del Instituto de la Patagonia, 4, 5-69.

Martinic, M. (2001). Patagonia Austral: 1885-1925. Un caso singular y temprano de integración regional autárquica. En Bandieri, S. (Ed.), Cruzando la cordillera (pp. 459486). Neuquén: CEHIR.

Martinic, M. (2011). Centenario del cierre de la misión de Dawson. Magallania, 39, 2, 97-103.

Martucci, M. (2016). Heterogeneidad especial en la misión salesiana Nuestra Señora de La Candelaria: Expresión de la identidad étnica selk'nam durante el proceso de contacto interétnico (Río Grande, Tierra del Fuego). (Tesis inédita de doctorado en arqueología). UNCPBA, Olavarría.

Rakita, G., Buikstra, J., Beck, L., \& Williams, S. (Eds). (2005). Interacting with the dead. Gainesville: University Press of Florida.

Ricoeur, P. (2004). Memory, history, forgetting. London: University of Chicago Press.

Salerno, M. (2011). Persona y cuerpo-vestido en la modernidad. (Tesis inédita de doctorado en arqueología). Universidad de Buenos Aires, Buenos Aires.

Salerno, M., Hereñú, D., Rigone, R., \& Guichón, R. (2017). Modelado 3D del cementerio de la misión salesiana Nuestra Señora de la Candelaria (Río Grande, Tierra del Fuego, Argentina). Virtual Archaeology Review. En prensa.

Salerno, M., \& Zarankin, A. (2015). Discussing the spaces of memory in Buenos Aires: Official narratives and the challenges of government management. En GonzálezRuibal, A. \& Moshenska, G. (Eds.) Ethics and the archaeology of violence (pp. 89-112). New York: Springer.

Scott, J. (1985). Weapons of the weak: Everyday forms of peasant resistance. New Haven: Yale University Press.

Silliman, S. (2005). Culture contact or colonialism? American antiquity, 70, 1, 55-74.

Taylor, W., \& Pease, F. (Eds). (1994). Violence, resistance, and survival in the Americas. Washington DC: Smithsonian Institution Press.

Thomas, N. (1991). Entangled objects: Exchange, material culture and colonialism in the Pacific. Cambridge: Harvard University Press.
Thomas, J. (2001). Archaeologies of place and landscape. En Archaeological theory today, editado por I. Hodder. Polity Press, Cambridge.

Weinrich, H. (2004). Lethe: The art and critique of forgetting. New York: Cornell University Press.

Williams, H. (2004). Death warmed up. Journal of material culture, 9, 3, 263-291.

\section{FUENTES CONSULTADAS}

\section{Inéditas}

Diario de la Misión Saleciana (DMS). Disponible en Museo Histórico y Natural Monseñor Fagnano (La Candelaria, Río Grande, Tierra del Fuego), [1896-1947].

Crónica del Padre Zenone (CZ). Disponible en Museo Histórico y Natural Monseñor Fagnano (La Candelaria, Río Grande, Tierra del Fuego), [1896-1947].

Libro de Defunciones II (LD II). Disponible en Museo Histórico y Natural Monseñor Fagnano (La Candelaria, Río Grande, Tierra del Fuego), [1896-1947].

\section{Éditas}

Beauvoir, J. (1915). Los Shelknam. Buenos Aires: Librería del Colegio Pío IX.

Bridges, L. (2000 [1948]). El último confín de la tierra. Buenos Aires: Sudamericana.

Darwin, C. (2008 [1909]). The voyage of the Beagle. New York: Cosimo.

Fernández, A. (2014). Con letra de mujer. La crónica de las hermanas de María Auxiliadora en la misión Nuestra Señora de la Candelaria (Tierra del Fuego - Argentina). Traducción al castellano, introducción y notas por Ana María Fernández. Buenos Aires: EDBA.

Gallardo, C. (1919). Los onas. Buenos Aires: Cabaut y Cía.

Gusinde, M. (1920a). Expedición a la Tierra del Fuego. En Publicaciones del Museo de Etnología y Antropología de Chile, 9-44.

Gusinde, M. (1920b). 2do Viaje a la Tierra del Fuego. En Publicaciones del Museo de Etnología y Antropología de Chile, 133-164.

Gusinde, M. (1951). Fueguinos. Sevilla: Escuela de Estudios Hispano-Americanos.

Gusinde, M. (1982 [1939]). Los indios de Tierra del Fuego, tomo I, vol. 2. Buenos Aires: Centro Argentino de Etnología Americana. 
